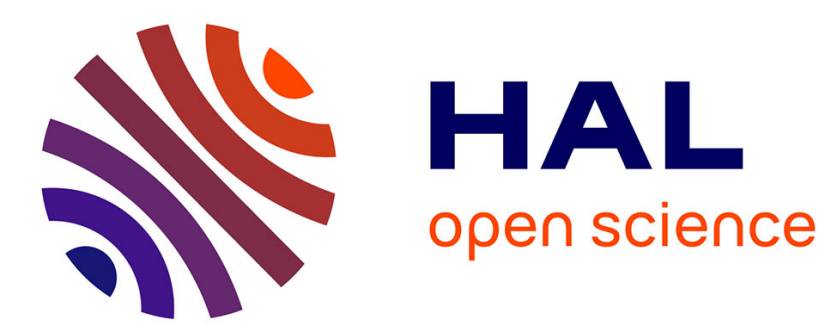

\title{
THE Ba-PROBLEM IN CVD-YBa2 Cu3 O7-[MATH] HTC SUPERCONDUCTORS
}

\author{
E. Fitzer, H. Oetzmann, F. Schmaderer, G. Wahl
}

\section{To cite this version:}

E. Fitzer, H. Oetzmann, F. Schmaderer, G. Wahl. THE Ba-PROBLEM IN CVD-YBa2 Cu3 O7[MATH] HTC SUPERCONDUCTORS. Journal de Physique IV Proceedings, 1991, 02 (C2), pp.C2713-C2-720. 10.1051/jp4:1991286 。 jpa-00249877

\section{HAL Id: jpa-00249877 https://hal.science/jpa-00249877}

Submitted on 1 Jan 1991

HAL is a multi-disciplinary open access archive for the deposit and dissemination of scientific research documents, whether they are published or not. The documents may come from teaching and research institutions in France or abroad, or from public or private research centers.
L'archive ouverte pluridisciplinaire HAL, est destinée au dépôt et à la diffusion de documents scientifiques de niveau recherche, publiés ou non, émanant des établissements d'enseignement et de recherche français ou étrangers, des laboratoires publics ou privés. 
Colloque C2, suppl. au Journal de Physique II, Vol. 1, septembre 1991

THE Ba- PROBLEM IN CVD-YBa $\mathrm{Cu}_{3} \mathrm{O}_{7}-\delta \mathrm{HT}_{\mathrm{C}}$ SUPERCONDUCTORS

\author{
E. FITZER ${ }^{*}$, H.OETZMANN** , F. SCHMADERER ${ }^{* *}$ and G. WAHL ** \\ *Institut für Chemische Technik der Universität Karlsruhe, \\ Germany \\ * Asea Brown Boveri AG, Corporate Research Heidelberg, \\ P.O. Box 1013 32, D-6900 Heidelberg 1, Germany \\ *** Institut für oberflächentechnik der Technischen, \\ Universität Braunschweig, Germany
}

\begin{abstract}
The evaporation behaviour of $\mathrm{Ba}$ (thd) 2 in a CVD-process for HTc-Superconductors is presented. The long-time stability as well as possibilities to increase the evaporation rates by changing the geometry of the evaporator and the process conditions are discussed.
\end{abstract}

\title{
Introduction
}

Investigations concerning Barium deposition are important for the CVD of $\mathrm{HT}_{\mathrm{C}}$-Superconductors. $\mathrm{Ba}$ (thd) ${ }_{2}$ i.e. barium bis(2.2.6.6-tetramethylheptane-3.5-dionate), $\mathrm{Ba}(\mathrm{hfac})_{2}$ i.e. barium bis(1.1.1.5.5.5-hexafluoropentane-2.4-dionate), $\mathrm{Ba}(\mathrm{hfod})_{2}$ i.e. barium bis(1.1.1.2.2.3.3-heptafluoro-7.7-dimethyloctane-4.6-dionate) /1/ as well as $\mathrm{Bal}_{2} / 2 /$ are possible candidates as precursors for the CVD process. However, most of the CVD experiments are carried out with $\mathrm{Ba}$ (thd) 2 , which has in comparison to the other compounds the advantage that it is free of fluorine (no fluoride formation !) and that the vapour pressure is sufficiently high. As has been shown recently $/ 3 / 4 /$ the alkaline earth $\beta$-diketonates show some irregularities in the evaporation behaviour and thus deviations of the stoichiometry in the gaseous educts. This causes Ba-free precipitates in the deposited layer, which reduce the superconducting crosssection. Another problem is the possible incorporation of carbon or carbonate into the layer due to incomplete desorption of decomposition products and the large thermodynamic stability of the carbonate. These questions are discussed with the help of microbalance evaporation experiments, by comparison of single deposition experiments with $\mathrm{HT}_{\mathrm{C}^{-}}$ deposition experiments and by thermodynamic calculations.

\section{Experimental equipments}

The evaporation experiments were carried out in a microbalance (type Setaram, accuracy $1 \mu \mathrm{g})$. The carrier gas $\left(\mathrm{Ar}+\mathrm{O}_{2}\right)$ flows from the bottom to the top with a typical flow rate of $19 \mathrm{l} / \mathrm{h}$ (STP) in a cylindrical stainless steel tube (internal diameter of $3.6 \mathrm{~cm}$ ) in an one zone oven with a heated length of $20 \mathrm{~cm}$. Because of the vertical temperature profile in the tube (lower temperature regions are above zones with higher temperatures) fluctuations in the gas atmosphere can appear /5/. The number which characterises the possible existence of those fluctuations is the Rayleigh number given by

$$
R a=\alpha \cdot g \cdot \Delta T \cdot H^{3} / D_{t h} \cdot v
$$


with $\Delta T=$ temperature difference, $D_{\text {th }}=$ thermal diffusivity, $\alpha=$ thermal expansion coefficient (= $1 / \mathrm{T}$ for ideal gases, $\mathrm{T}=$ absolute temperature), $\mathrm{g}=$ acceleration due to gravity, $\mathrm{H}=$ height of the reactor, $v=$ kinematic viscosity. According to $/ 5 /$ for $\mathrm{Ra}>5 \cdot 10^{3}$ fluctuations are expected. At a working pressure of $10 \mathrm{hPa}$ for air the calculated Rayleigh number is $R<1000$, that means the system is in the stable range. At $p=1000 \mathrm{hPa}$ a value of $\mathrm{Ra} \gg 5 \cdot 10^{3}$ is estimated and fluctuations are possible. This was verified by measurement of the time dependence of the temperature with a thermocouple $(\phi 0.5 \mathrm{~mm})$ mounted in the center of the heated tube. Fluctuations were found at $p=1000 \mathrm{hPa}$ with a mean frequency of 0.1 cycles $/ \mathrm{s}$ in accordance with values known from the literature $/ 5 /$. At the pressure of $\mathrm{p}=10 \mathrm{hPa}$ no fluctuations are found. Therefore, the microbalance measurements were carried out in the range of $10 \mathrm{hPa}$, which is also the working pressure of the CVD experiments.

The chelate compounds, purchased from different companies (STREM, TNO, Solvay), were made from water containing and alternatively from water free solutions. They were filled in $\mathrm{N}_{2}$ atmosphere into the stainless steel container (evaporator) with a diameter and a depth of 10 $\mathrm{mm}$ up to a height of app. $50 \%(\sim 200 \mathrm{mg})$ and then arranged in the microbalance.

The CVD-experiments were carried out in the equipment described elsewhere /4/. The main part is a stagnation flow reactor with cold walls. The deposition surface has a diameter of 1.5 $\mathrm{cm}$. Two types of evaporators, shown in fig. $1 \mathrm{a} / \mathrm{b}$, have been used. The gas flow has no direct contact to the powder using the evaporator (a) in contrast to the evaporator (b), where the gas can flow through holes directly above the powder surface. It is shown later that the evaporation rates in the evaporator (b) are much higher in comparison to the evaporator (a). All tubes between the evaporators and the CVD-reactor were heated up to about $250^{\circ} \mathrm{C}$, some degrees higher than the highest evaporation temperature.

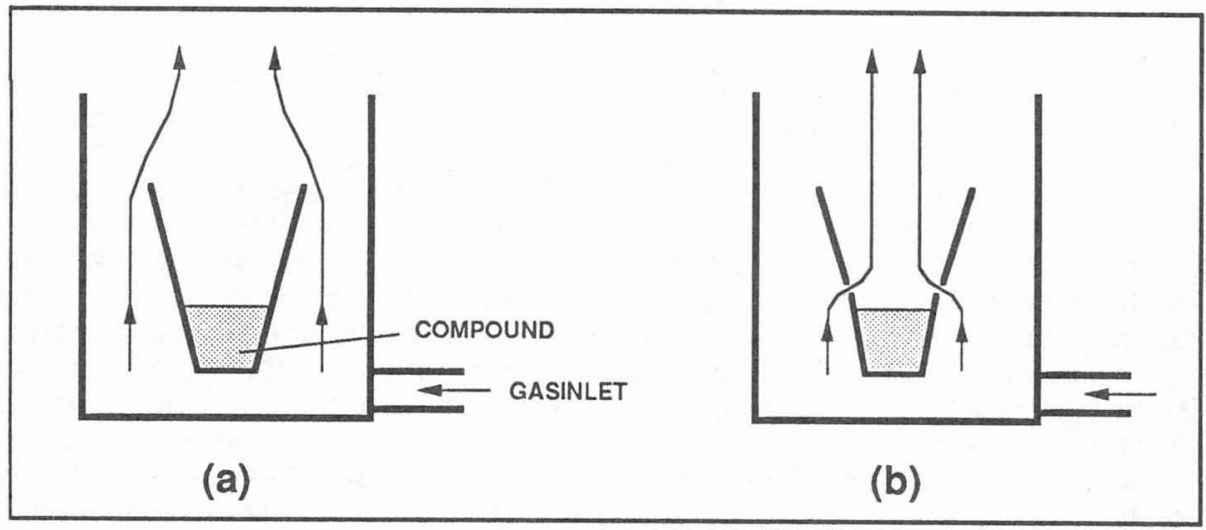

Fig. 1: Different types of evaporators used

\section{Microbalance experiments}

Fig. 2 shows a typical evaporation curve of $\mathrm{Ba}(\text { thd })_{2}$. During the heating-up period a very strong weight loss exists with large evaporation rates. After this heating up period the curve becomes flatter and the rate decreases more slowly. Mass spectrometric measurements during the heating up period have shown that $\mathrm{H}_{2} \mathrm{O}$ and $\mathrm{H}($ thd) evaporates in the case of using compounds made from water containing solutions. Due to the good correlation between the total mass loss of the powder and the deposition rate, as was found in $/ 4 / 6 /$, it can be assumed that in addition Ba-compounds evaporate during this heating up period. The decreasing 
evaporation rate with time, also at constant temperature, depends strongly on the temperature range as is shown in fig. 3. Constant evaporation rates can be expected only at temperatures about $\mathrm{T}=200^{\circ} \mathrm{C}$ using the source materials investigated.

The origin for the time dependence of the evaporation rates can be twofold:

1.) In the case of compounds which are made from water containing solutions - indicated by open squares in fig. 3 - hydrolysis of the $\mathrm{Ba}(\text { thd })_{2}$ is possible $/ 7 /$.

2.) Due to the fact that the decrease of the evaporation rate exists for all compounds, independent on the production method, it is probable that polymerization or decomposition in the condensed phase is the main cause for the decrease of the evaporation rate.

Both effects cause an increase of the $\mathrm{Ba}$ content in the rest of the precursor after the evaporation experiment. The compound (as purchased) and the rest after the evaporation experiment, which was carried out in an evaporator similar to fig. 1b, was analysed by Atomic Absorption Spectroscopy (AAS, Fa. Beckman). The compound was dissolved in a mixture of acetone/water and $\mathrm{HCl}$. The $\mathrm{Ba}$ mass content of the new powder was found to be $26.3 \pm .03 \%$ in good accordance with the theoretical value of $\mathrm{Ba}(\text { thd })_{2}$ of $27.25 \%$. After an evaporation

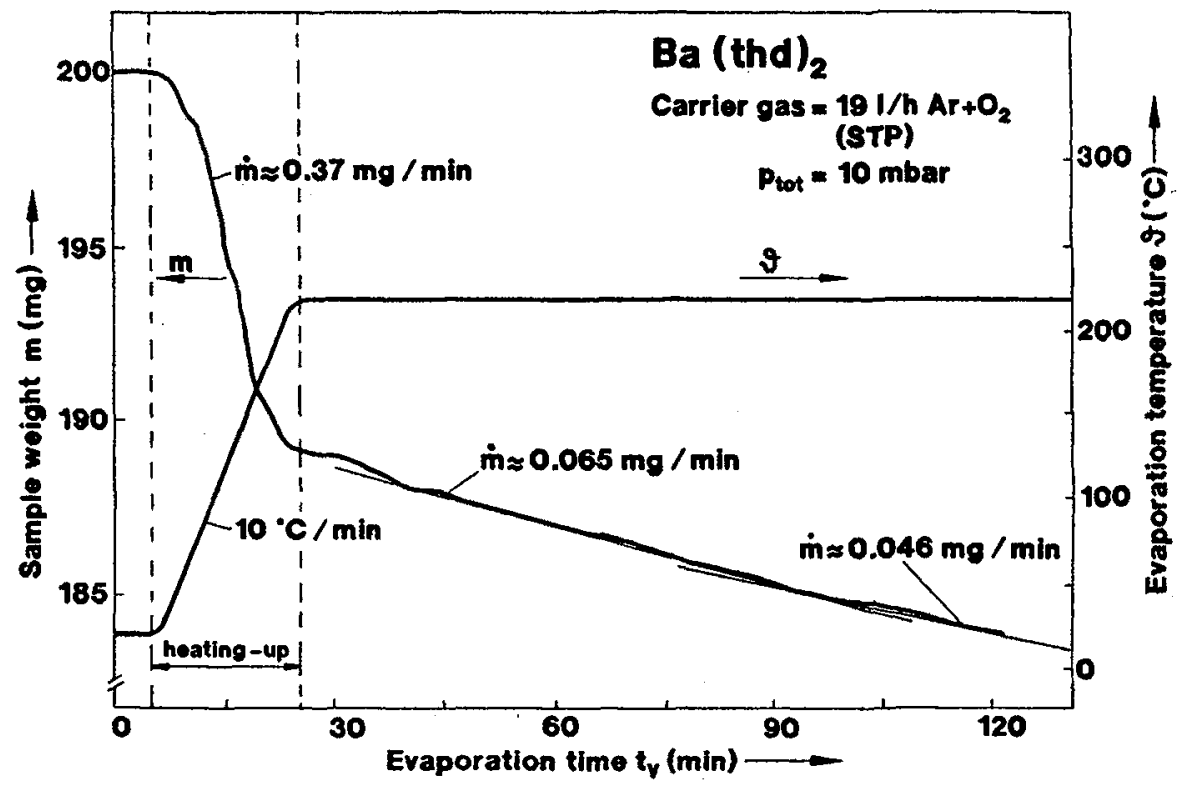

Fig. 2: Typical evaporation curve of $\mathrm{Ba}(\text { thd })_{2}$

experiment at $T_{v}=220^{\circ} \mathrm{C}$ and a time of $1.5 \mathrm{~h}$ the mass content of $\mathrm{Ba}$ was increased to $35.7 \%$. Hydrolysis and polymerization can be reduced by adding gaseous $H($ thd $)$ during the evaporation experiment $/ 3 / 6 /$. For these investigations the Ar gas flow (25 l/h STP) was enriched with $\mathrm{H}$ (thd) with a content of approx. $1 \%$ before entering the evaporator. The total molar evaporation rates could be stabilized and increased as shown in fig. 4 . For these experiments the evaporator in fig. 1a was used. The molar evaporation rates were calculated from the total mass change under the assumption that $\mathrm{Ba}(\mathrm{thd})_{2}$ (molar mass $503 \mathrm{~g} / \mathrm{mol}$ ) evaporates. In addition the activation energy is smaller compared to the evaporation without adding $H($ thd $)$ as shown in fig. 5. At higher temperatures, however, the effect of $H($ thd) disappears. 


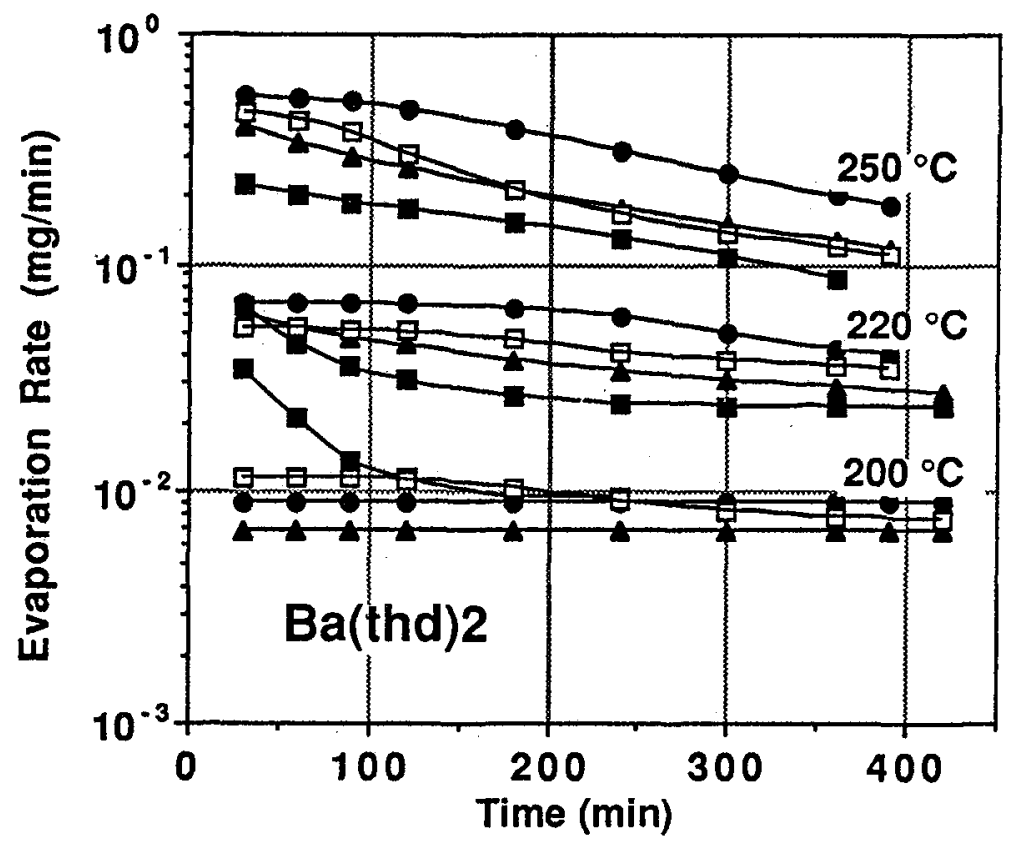

Fig. 3: Evaporation curves of $\mathrm{Ba}(\text { thd })_{2}$ from different suppliers
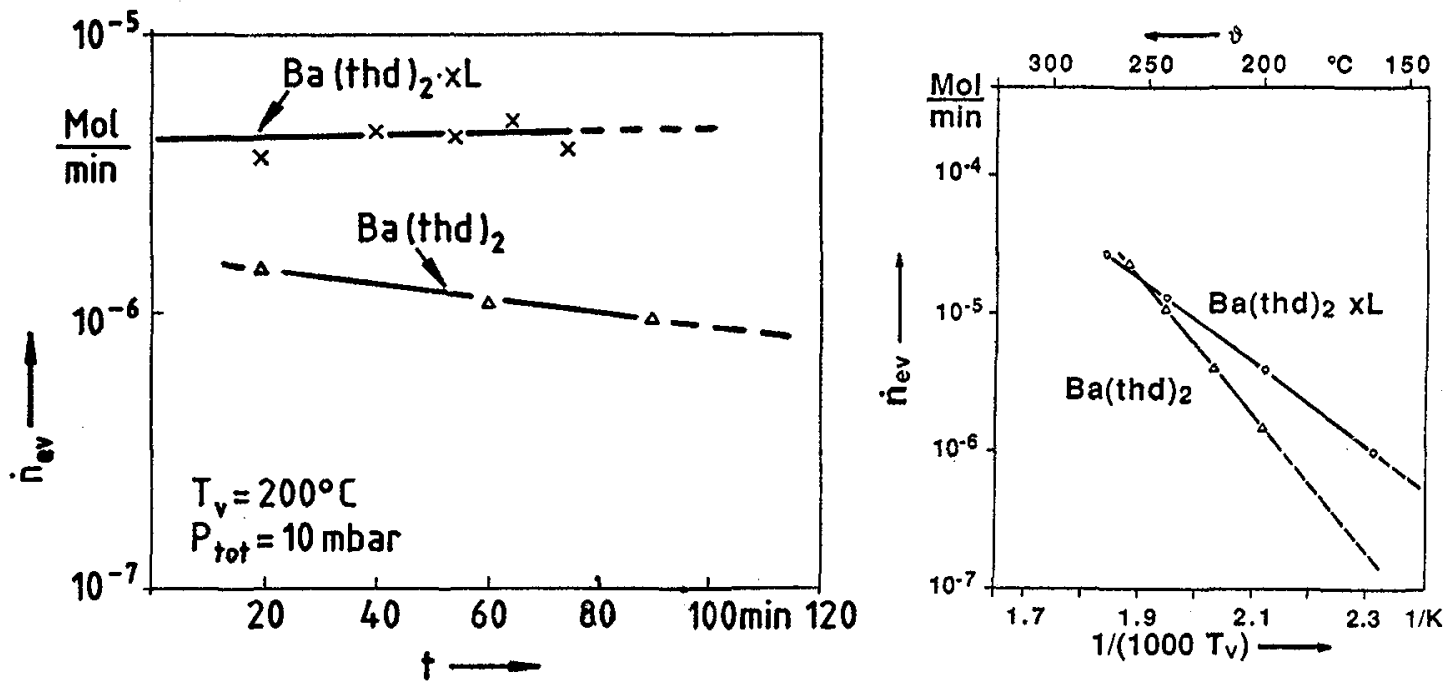

Fig. 4: Molar evaporation rates versus time

Fig. 5: Arrhenius plot of the $\mathrm{Ba}$ (thd $)_{2}$-evaporation (with and without $H($ thd)) 


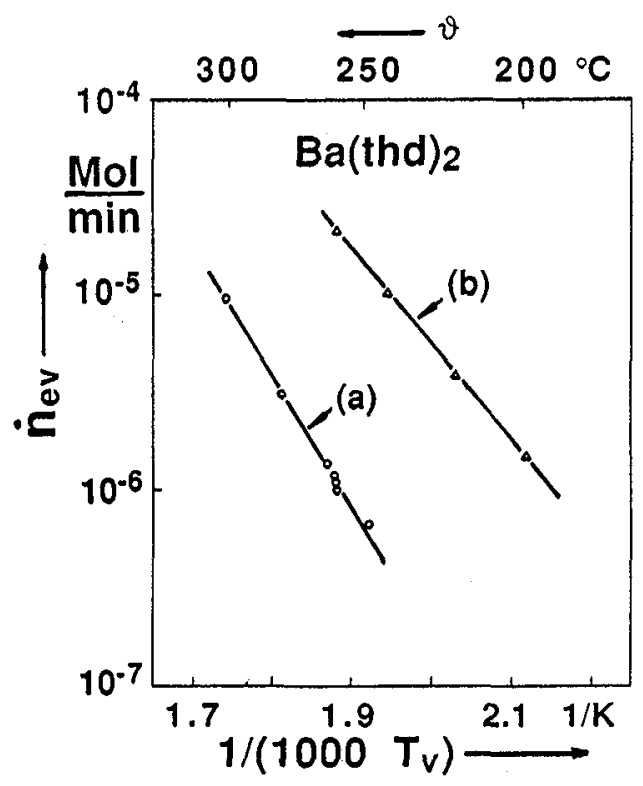

Fig. 6: Evaporation behaviour of $\mathrm{Ba}(\text { thd })_{2}$ using the evaporators shown in fig. $1 \mathrm{a}, \mathrm{b}$

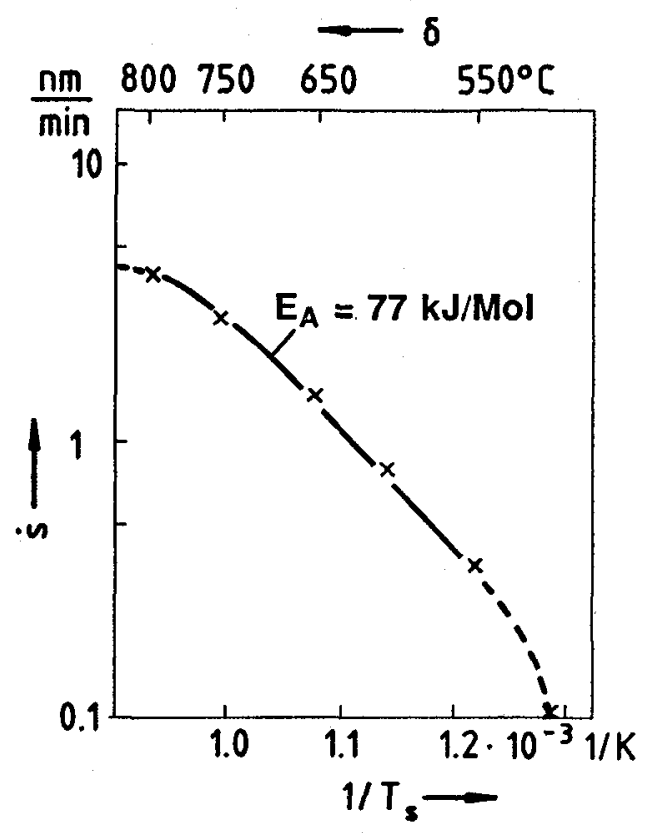

Fig. 7: $\mathrm{BaO} / \mathrm{BaCO}$-deposition rate versus the reciprocal absolute deposition temperature

These results show, that it is difficult to increase the concentration of $\mathrm{Ba}(\text { thd })_{2}$ in the gas phase by increasing the evaporation temperature. In order to reach a constant evaporation rate, temperatures $\mathrm{T} \leq 200^{\circ} \mathrm{C}$ should be chosen. The maximum concentration which is possible in the gas atmosphere is given by the equilibrium vapor pressure and can only be reached by optimized evaporation conditions. By using the changed gas flow behaviour in the evaporation geometry in fig. $1 \mathrm{~b}$ instead of fig. 1a the evaporation rates increased significantly as shown in fig. 6.

\section{Single deposition experiments}

The experiments were carried out in the equipment described elsewhere /3/4/ where only one of the three evaporators was filled with the source material. As substrates polished $Y$ stabilized polycristalline $\mathrm{ZrO}_{2}$ wafers were used. The thickness growth rate $\dot{\mathrm{s}}$ was calculated from the weight change $\Delta m$ of the sample

$$
\dot{s}=\Delta \mathrm{m} / \mathrm{\rho}(\mathrm{BaO}) \cdot A \cdot \mathrm{t}
$$

with $\Delta \mathrm{m}=$ mass change, $\rho(\mathrm{BaO})=$ density of $\mathrm{BaO}=5.72 \mathrm{~g} / \mathrm{cm}^{3} / 8 /, \mathrm{A}=$ deposition surface, $t=$ deposition time. Fig. 7 shows the deposition rate vs. the temperature. In an Arrhenius plot the temperature dependence can be described by an activation energy of $77 \mathrm{KJ} / \mathrm{mol}$. The $x$-ray analysis shows that in the total temperature range a mixture of $\mathrm{BaO}, \mathrm{BaO}_{2}$ and $\mathrm{BaCO}_{3}$ was deposited. For the analysis the JCPD-file was used $19 /$. The results were verified by XPS measurements.

In the case of the deposition of the HTc-superconductor /4/ $x$-ray and XPS measurements show no carbon or carbonate in the layer in contrast to the single component experiments. 


\section{Discussion}

a) The increase of the evaporation rates by changing the evaporator geometry

The difference in the evaporation behaviour can be explained by the model shown in fig. 8 . In the case of the evaporator shown in fig. $1 \mathrm{a}$ it can be assumed that in the container a standing gas atmosphere exists and the evaporating molecules can only reach the evaporator outlet by diffusion. The reduction of the evaporation by this gas layer can be estimated by a kinetic model as follows. The molecular surface density of evaporating molecules is $i_{1}$. Near the surface a gas concentration $n_{1}$ of $\mathrm{Ba}$ containing molecules is formed by the competition of evaporation and diffusion. Outside of the container the concentration $\mathrm{n}_{10}$ of $\mathrm{Ba}$ containing molecules is much smaller because of the dilution by the free flowing gas. The value outside the container is approximated to be $n_{10}=0$. The molecules near the evaporation surface diffuse into the free flowing gas according to the diffusion law:

$$
\mathrm{i}_{1 \mathrm{~d}}=\mathrm{D} \cdot \mathrm{n}_{1} / \mathrm{d} \text {, }
$$

where $D$ is the diffusion coefficient of the Ba-containing molecules and $d$ is the distance between the evaporation surface and the opening of the container, or they condense again on the evaporation surface according to the law $/ 10$ /

$$
i_{1 c}=n_{1} \cdot v / 4 \text {, }
$$

where $v$ is the mean thermal velocity of the Ba-containing molecules. In the steady state the following equation must be correct:

$$
i_{1}-i_{1 c}=i_{1 d} .
$$

From this equation the concentration $n_{1}$ can be calculated:

$$
n_{1}=\frac{i_{1}}{(D / d+v / 4)}
$$

The evaporation rate into the free flowing gas is then:

$$
i_{t d}=\frac{D}{d} \cdot \frac{i_{1}}{(D / d+v / 4)}
$$

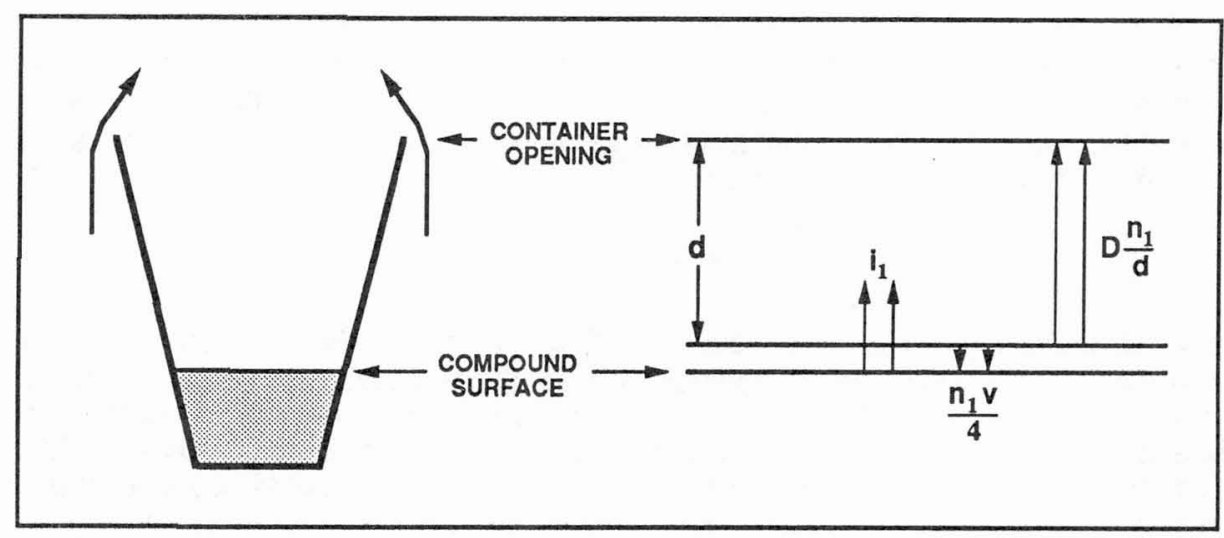

Fig. 8: Model for the evaporation behaviour using the evaporator in fig. 1 a 
With the help of the relation for the diffusion coefficient /10/

$$
D=\lambda \cdot v / 3
$$

( $\lambda$ is the mean free path of the molecules, app. $10^{-3} \mathrm{~cm}$ at $10 \mathrm{hPa}$ in $\mathrm{Ar}$ ), the relation for $\mathrm{i}_{1 \mathrm{~d}}$ can be simplified:

$$
i_{1 d}=\frac{i_{1}}{(1+0.75 \cdot d / \lambda)}
$$

This formula shows that the evaporation can be strongly enhanced by decreasing $d$ at a fixed pressure. This effect is shown fig. 6 where the enhancing of the evaporation is shown by decreasing the effective length $d$.

\section{b) Carbonate formation}

In order to estimate the possible carbonate formation during the deposition thermodynamic calculations were made. The thermodynamic data stored in the computer code microtherm $/ 11 /$ and for the $\mathrm{HT}_{\mathrm{c}}$ superconductor the data given in $/ 12 /$ were used. The computer code Chemsage /13/ was used for the calculation of the thermodynamic equilibrium. For the single component deposition typical molar flows in the gas phase were assumed: $i_{\left(0_{2}\right)}=0.8 \mathrm{~mol} / \mathrm{h}$, $i_{(A r)}=1.78 \mathrm{~mol} / \mathrm{h}, i_{\left(B a(t h d)_{2}\right)}=1.19 \cdot 10^{-4} \mathrm{~mol} / \mathrm{h}, \mathrm{i}_{(H(t h d))} \approx 10^{-2} \mathrm{~mol} / \mathrm{h}$ and a total pressure of 10 hPa. In the case of the $\mathrm{HT}_{\mathrm{C}}$-deposition an $\mathrm{Y}(\text { thd })_{3}$ flow rate of $5.9 \cdot 10^{-5} \mathrm{~mol} / \mathrm{h}$ and a $\mathrm{Cu}(\mathrm{thd})_{2}$ flow rate of $1.78 \cdot 10^{-4}$ was added. These deposition conditions correspond to the experimental conditions in the experiments here and elsewhere /4/. For the thermodynamic calculation the formation of the following compounds was taken into account: in the gas phase: $\mathrm{Ar}, \mathrm{H}, \mathrm{H}_{2}, \mathrm{O}_{2}$, $\mathrm{O}_{3}, \mathrm{H}_{2} \mathrm{O}, \mathrm{H}_{2} \mathrm{O}_{2}, \mathrm{CO}, \mathrm{CO}_{2}, \mathrm{CH}_{4}, \mathrm{Y}, \mathrm{Ba}, \mathrm{BaO}, \mathrm{BaOH}, \mathrm{Ba}(\mathrm{OH})_{2}, \mathrm{Cu}, \mathrm{CuO}$ and in the condensed phase: $\mathrm{Y}, \mathrm{Y}_{2} \mathrm{O}_{3}, \mathrm{Ba}, \mathrm{BaO}, \mathrm{BaO}_{2}, \mathrm{Ba}(\mathrm{OH})_{2}, \mathrm{BaH}_{2}, \mathrm{BaC}_{2}, \mathrm{BaCO}_{3}, \mathrm{Cu}, \mathrm{CuO}, \mathrm{Cu}_{2} \mathrm{O}, \mathrm{Cu}(\mathrm{OH})_{2}$ and the superconductor. Fig. 9 shows as a result of the thermodynamic calculations the border line

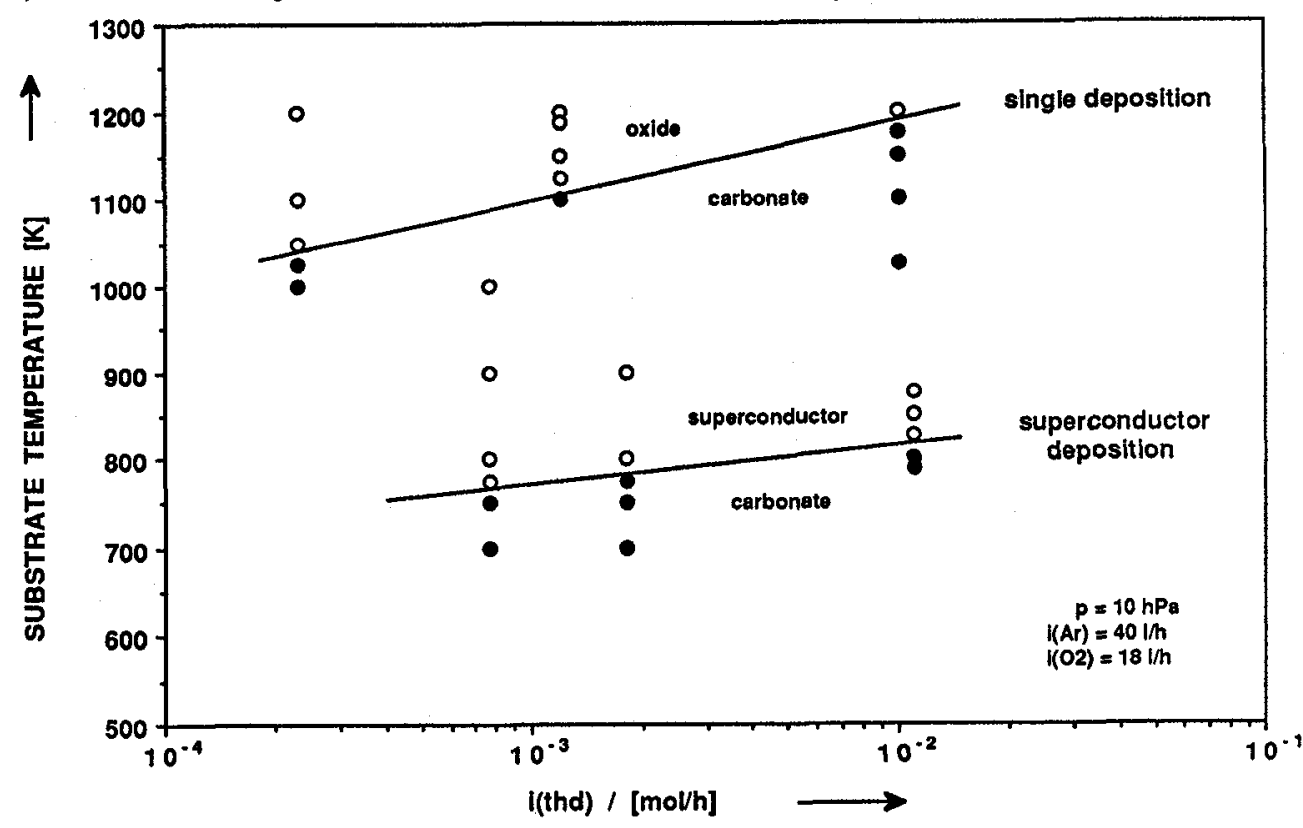

Fig. 9: Calculated borderline between carbonate- and oxide-formation 
between the BaO-, superconductor- and carbonate formation in dependence on the total (thd) -content in the gas phase. In accordance with our experimental results the carbonate/oxide borderline is shifted to lower temperatures in the case of the superconductor deposition because of the higher thermodynamic stability of the superconductor. Only at temperatures below $800 \mathrm{~K}$ carbonate formation can be expected.

\section{Literature:}

/1/ M.L. Hitchman, D.D. Gilliland, D.J. Cole-Hamilton, S.C. Thompson; Inst.Phys.Conf.Ser. No.111, p.305; Proc. Int. Conf. on New Materials and their Applications, Warwick, 1990

12/ M. Ottoson, A. Hartsta, J.O. Carlsson

Proc. XI, Int. CVD Conf. ed. by K.E. Spear, G.W. Cullen, 1990, ECS, Pennington, p.180

13/ F.Schmaderer; PhD-Thesis, Univers. Karlsruhe, 1990

14/ F. Schmaderer, H. Oetzmann, R. Huber, G. Wahl; this Volume

15/ J.P. Dismukes, B.J. Curtis; Silicon Conf., ECS, Princeton, 1973, p.258

/6/ F. Schmaderer, R. Huber, H. Oetzmann, G. Wahl Proc. XI Int. CVD-Conf. ed. by K.E. Spear, G.W. Cullen, ECS, Pennington 1990, p.211

I7! S.B. Turnipseed, R.M. Barkley, R.E. Sievers, Synthesis and Characterization of Alkaline Earth $\beta$-diketonate Metal Complexes used as Precursors for CVD of Thin film Superconductors; to be published

18/ Handbook of Chemistry and Physics, CRC Press 58th Edition, 1977-1978

19/ Joint Committee on Powder Diffraction Standards, Powder Difraction File Search Manual, Swarthmore, Pennsylvania 19081, USA, 1974

110/ E.A. Moelwyn-Hughes; Physical Chemistry, Pergamon Press, 1961

$/ 11$ B. Chynet, M. Simons, K. Hack; distributed from Therdas, TU-Aachen

/12/ L.R. Moos, D.C. Sonnenberger, R.J. Thorn; Inorg. Chem. 27 (1988) 2106

113/ G. Eriksson, K. Hack; Chemsage, distributed from Therdas, TU Aachen 